\section{Tecnologías imaginadas. Discusiones entre mutantes digitales}

AUTORES / AUTHORS

Juan López-López

EDITORIAL / PUBLISHING COMPANY

Bogotá D.C., Ediciones USTA, 2017, 161 pp.

https://repository.usta.edu.co/handle/11634/12043
Recibido / Received 28 de mayo de 2020

- Aceptado / Acepted 6 de junio de 2020

- Páginas / Pages De la 369 a la 371

- ISSN: 1885-365X

Esta obra pretende mostrar el panorama general de los estudios llevados a cabo entre finales del siglo xx y comienzos del xxı sobre el manejo de las tecnologías digitales para, a partir de aquí, fortalecer estudios venideros al agregar a la formula de estudio un enfoque histórico cultural. Este consiste en estudiar la narrativa de los usuarios al usar las tecnologías, siendo estos los que determinan el alcance de las funciones de los dispositivos y, asimismo, la significación social que estructura toda una cultura digital con sus problemas y aciertos, evidenciados aquí desde la mirada de diversos grupos de estudiantes de la USTA.

El contenido del libro está dividido en seis capítulos y varios subcapítulos. El primero contrasta las tendencias de los estudios sobre las tecnologías digitales y su relación con la educación a lo largo de los años para, a continuación, discutir la pertinencia del enfoque analítico utilitarista frente a un enfoque cultural cada vez más común. El segundo capítulo se inicia con una serie de precisiones teóricas a modo de justificación para llevar a cabo un estudio de tipo cualitativo, cuya metodología y proceso de muestreo son expuestos tras postular las bases teóricas necesarias. El capitulo tres arroja de forma general los resultados del estudio a través de una reconstrucción histórico-cultural de las distintas relaciones entre los estudiantes con las tecnologías digitales. El cuarto capítulo se concentra en estudiar la manera en que se construyó el imaginario cultural de la juventud acerca de lo que se podía, o no, hacer con las tecnologías, al ser influenciados por diversos grupos y espacios culturales (macro y micro culturas). El capitulo cinco estudia la forma en que las tecnologías han afectado la vida de los jóvenes en el plano comunicativo e identitario, mostrando los pros y contras que se presentan a la juventud de un mundo cada vez mas tecnificado. Finalmente, el capitulo seis está dedicado a las conclusiones de la obra.

Al recorrer la historia de los estudios digitales hechos en Colombia el capitulo uno concluye que el centralismo de las investigaciones sobre la obtención material de tecnologías enfocado en estudiar la disminución de la brecha tecnológica, debe ser remplazado por una perspectiva teórico-metodológica que estudie la forma en que las tecnologías afectan las relaciones de identidad y comunicación de los jóvenes. Esto implica reconocer a los usuarios como agentes activos en la formación de imaginarios digitales, pues es la sociedad en conjunto la que decide cómo deben ser usadas estas tecnologías dentro de la cultura. 
Una vez entendidos los usuarios como sujetos discursivos inmersos en una narrativa social, el capitulo dos instaura las metodologías y el guion para hacer un análisis hermenéutico del discurso a partir de una serie de preguntas hechas a un total de 116 estudiantes. Entre las preguntas encontramos una clara división temática entre las que tienen que ver con la tecnología, el cambio social y la vida cotidiana, aquellas que versan sobre el mundo actual, y por último, las interrogantes sobre la tecnología digital y la educación. El capitulo cierra explicando la organización de los estudiantes en grupos de discusión que fueron grabados a lo largo de 5 meses.

El capítulo tres es claro al mostrar la ambivalencia de las tecnologías como armas de doble filo para los individuos y la sociedad en general, pues según cómo se utilicen, o se representen en el imaginario social, aparecen situaciones ya sean de carácter negativo o positivo. En cuanto al uso como herramienta, recordemos la novedad que representó el adelanto de la web 2.0 que propició una conexión a larga distancia entre todas las personas que poseían un aparato con conexión a internet a la vez que provocaba paulatinamente una seria dependencia de las redes sociales. Además, esta web también representó el inicio de lo que hoy se conoce como sobre información que provocó una migración de los usuarios desde la facilidad a la hora de conseguir datos útiles y fiables a la pereza debido a la cantidad de páginas fake que iban apareciendo con el pasar de los años y la cantidad de shitposting en forma de videos e imágenes que hicieron uso de internet en su gran parte para el entretenimiento. Por otro lado, la capacidad de renovarse constantemente hizo que el imaginario social estuviera dominado por un constante deseo de renovación por parte de los usuarios quienes alimentaron, quizá sin saberlo, una jerarquía de prestigio en que dominaban aquellos con la última tecnología. El capitulo cierra discutiendo el proceso constructivo de la identidad una vez instituido el acceso casi común a un mundo digital y globalizado. Siendo el mundo así, ahora cada quien puede representarse cuándo y cómo quiera en un proceso dinámico donde los usuarios más activos logran sobresalir como actores simbólicos (youtubers, blogguers, etc.), mientras los menos activos viven dentro de un proceso de exclusión paulatina que demuestra una vez más el carácter ambivalente de las tecnologías siempre presentes en este mundo cada vez mas tecnificado.

Ahora bien, la importancia del capítulo cuatro es determinar la manera en que se formó la conciencia social y entender que esta es, en suma con las características intrínsecas de la tecnología, la representación verdadera de lo que son los aparatos digitales en el mundo actual. Es necesario aclarar que no hay un solo imaginario tecnológico, pues cada grupo (amigos, maestros, familia, etc.) y espacio (universidad, centros comerciales, colegios, etc.) busca construir una manera de relacionarse con los medios digitales, por lo tanto la visión que tiene un adulto frente a la que tiene un joven es, en muchos casos, diametralmente opuesta. En ese sentido, resultan más importantes las enseñanzas y ejemplos de las microculturas (familia y amigos), pues al ser más cercanas al individuo son acogidas con más facilidad y estas son las que determinan la manera en que se usarán las tecnologías ya sea en el trabajo o en el tiempo libre.

El capítulo cinco demuestra nuevamente el carácter ambivalente de las tecnologías al concentrarse en la forma en que estas afectaron la comunicación entre personas apareciendo conceptos como presencia-ausencia y ausencia-presencia referentes a estados de comunicación en que la corporeidad puede aparecer o desaparecer según sea la manera 
de usar un medio comunicativo para acercar a alguien lejano a través de la conexión que ofrece internet o alejar a alguien que se tiene al lado gracias al vicio de nunca dejar de ver la pantalla del celular. Aquí lo remarcable, si tenemos en cuenta que los imaginarios sociales son constructos, es que ambas circunstancias dependen de los usuarios y la manera en que estos entienden la comunicación, por ello lo mejor es que cada uno encuentre el equilibrio, o bien aprenda de los usuarios mejor experimentados con el fin de no crear ningún tipo de vicio.

Las conclusiones retoman los temas de los anteriores capítulos para afirmar, entre otras cosas, que los jóvenes ubicados entre la anterior generación, aquella que no supo adaptarse a la llegada de las nuevas tecnologías, y la más nueva, aquella que nació inmersa en un mundo tecnológico, está compuesta por lo que se denomina en la obra como mutante digital, individuos a caballo en un mundo que se les ofrece tan devastador como útil. Hace hincapié además en el hecho de que estos jóvenes requieren y piden las ayudas necesarias para integrar sus saberes en pos de manejar correctamente esos medios y así poder fomentar entre todos una cultura consciente y sensible ante las problemáticas que siguen apareciendo con cada avance tecnológico y para ello el autor vuelve sobre la propuesta inicial de cambiar el enfoque centralizado en la tecnología para poner el foco sobre la humanidad, pues entre todos podemos capturar y redireccionar esos imaginarios sueltos que han crecido sin el debido control o tan siquiera la atención que merecen.

\section{Bibliografía}

LÓPEZ LÓPEZ, Juan Sebastián (2017). Tecnologías imaginadas. Discusiones entre mutantes digitales. Bogotá D.C.: Ediciones USTA. ISBN: 978 9587820164. DOI: 10.2307/j.ctvb939b6

Por Brian Yagarí

Universidad Santo Tomás, Bogotá (Colombia)

@ brayanrodriguezy@usantotomas.edu.co (iD 0000-0002-4294-9834 